\title{
CONSIDERACIONES EXTRAVAGANTES DE UN «JURISTA EMPÍRICO»*
}

\author{
Salvatore Senese ** \\ Presidente de la Sección de Derecho del Trabajo del Tribunal de Casación Civil
}

RESUMEN. El autor destaca los aspectos de la obra de FERRAJOLI que son de particular interés para un «jurista empírico». En particular se trata el método axiomatizado, el cual aparece como satisfaciendo la exigencia de transparencia que requiere el ejercicio del margen ineliminable de libertad del intérprete. Como ejemplo de la fecundidad de dicho método, el autor se refiere a la forma en que FERRAJOLI pone a la guerra sub specie iuris. Igualmente, dicho método aparece como una respuesta satisfactoria a los problemas de inflación, desorden legislativo y pluralismo de los ordenamientos. Por último, el autor hace una observación a favor del rechazo de FERRAJoli de la fórmula de ALEXY, de acuerdo con la cual una norma pierde validez si es sumamente injusta; $y$ formula tres preguntas para FERRAJOLI sobre la separación de poderes y las leyes de interpretación auténtica, sobre el contrato de trabajo subordinado y sobre las lagunas y sus remedios.

Palabras clave: FERRAJOLI, derechos fundamentales, Derecho internacional, interpretación auténtica, contrato de trabajo, lagunas.

ABSTRACT. The author underlines those aspects of FERRAJOLI's work which are of particular interest to an «empirical jurist». What is particularly dealt with is the axiomatized method, which appears to satisfy the demand for transparency required by the exercise of the interpreter's uneliminable margin of freedom. The author refers to the way in which FERRAJOLI subjects war sub specie juris as an example of the fecundity of the above method. Similarly, the same method appears to be a satisfactory answer to the problems of inflation, legislative disorder and the pluralism of legal systems. Lastly, the author makes a comment in favour of FERRAJOLI's rejection of ALEXY's formula, according to which a norm loses validity if it is profoundly unjust. He also poses three questions to FERRAJOLI about the separation of powers and authentic interpretation norms, about the subordinated employment contract, and about gaps and how to solve them.

Keywords: FERRAJOLI, fundamental rights, international law, authentic interpretation, employment contract, gaps.

* Fecha de recepción: 1 de diciembre de 2008. Fecha de aceptación: 18 de diciembre de 2008.

** Este trabajo va a ser publicado también en el Homenaje al profesor Modestino ACONE. 


\section{UNA PREMISA}

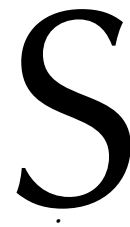

oy un jurista empírico, profesionalmente comprometido con el tipo de interpretación de las normas que L. FERRAJOLI llama «interpretación operativa» y que consiste en la aplicación del Derecho al caso concreto.

Un jurista, pues, distante, por formación, cultura y práctica profesonal, del universo cultural de una teoría axiomatizada del Derecho.

Siendo así, quizá tenga algún sentido, para los teóricos y filósofos del Derecho y de la política aquí reunidos para discutir sobre Principia iuris, hacer hincapié en los concretos motivos de interés que una obra como ésta suscita en un jurista de ese perfil, en una primera lectura, necesariamente apresurada.

\section{EL MÉTODO Y LA LIBERTAD DEL JUEZ}

\section{Comenzaré por el método.}

El método axiomatizado, rigurosamente formal y por tanto avalorativo, en su aplicación, en la derivación de los teoremas y en el uso de los conceptos, en la construcción, en suma, de una sintaxis del discurso jurídico. Pero en absoluto avalorativo - itodo lo contrario! - en la formulación de las llamadas tesis primitivas, cuyo desarrollo está regido por aquel método y sus rigurosas reglas formales.

Un método semejante, por sorprendente que pueda resultar, responde a una exigencia cada vez más sentida por el jurista empírico. Éste, como advierte el autor, se encuentra vinculado por el léxico del lenguaje legal, pero la creciente cantidad y heterogeneidad del material legislativo y de sus fuentes de producción, en conjunción con la también creciente imprecisión y polisemia del lenguaje en que el mismo se expresa, constriñe cada vez más al jurista a recurrir a términos y categorías conceptuales de la teoría del Derecho para interpretarlo y atribuirle sentido. Éstas son producto de una tradición plurisecular, en la que los significados han ido estratificándose y contaminándose, lo que les hace fuertemente imprecisos y polisémicos, hasta el punto de que los conceptos correspondientes resultan ambiguos e incluso indeterminados. Y, en las conclusiones operativas que de ellos se extraen, dejan espacio a opciones e inclinaciones subjetivas del intérprete, con frecuencia no del todo conscientes.

El margen ineliminable de libertad ínsito en toda actividad interpretativa, y singularmente en la interpretación jurídica, en especial cuando se trata de ordenamientos complejos y estructurados en distintos niveles, acaba siendo cubierto de un modo arbitrario por inconsciente, y por tanto no presidido por la razón y los cánones constitucionales. En efecto, el imperativo de sujeción del juez a la ley y la teoría de la separación de poderes exigen que el espacio propio del intérprete sea llenado por el juez. Que debe hacerlo con exclusión de cualquier connotación arbitrariamente subjetiva, en conformidad con una línea de coherencia con los materiales normativos recabados de las diversas fuentes, seleccionados con respeto de su propia jerarquía, según una regla que impone elegir, de todos los significados posibles, el más congruente con los preceptos constitucionales o supraordenados. Así pues, atribución de varios significados posibles, control de 
cada uno de ellos a la luz del conjunto de los datos normativos relevantes, y, en fin, opción conforme a los valores constitucionales. Son los pasos a través de los que se ejercen, se autolimitan y se hacen transparentes y, por tanto, controlables, las inevitables opciones ético-políticas del juez. Y bien, una exigencia semejante de transparencia de las opciones y de rigor en las consecuencias que de ellas se deriven, encuentra su máximo realización en el método axiomático construido por FERRAJOLI. El espacio para las opciones ético-políticas está aquí rigurosamente limitado a la formulación de las tesis primitivas o indemostradas (que obviamente están justificadas por otros factores, principalmente por su capacidad explicativa). El carácter opcional de la estipulación de tales tesis aparece tan explícitamente declarado, como, avalorativa y lógicamente obligada es, en cambio, la derivación analítica de los sucesivos desarrollos del discurso teórico.

\section{EL MÉTODO Y LA GUERRA SUB SPECIE IURIS}

Hay un ejemplo particularmente esclarecedor de la fecundidad de ese método en las páginas que FERRAJOLI dedica a la guerra. Tras de haberla definido, en el plano teórico general, como antítesis o negación del Derecho, la examina desde el punto de vista del actual Derecho internacional y constitucional italiano, poniendo de relieve que uno y otro — cabe decir que éste como consecuencia de aquél— han positivizado la prohibición de la guerra de agresión, haciendo de este modo que el principio de la paz, haya pasado, de fundamento lógico y axiológico de aquélla, a ser fundamento de derecho positivo de los respectivos ordenamientos. Con la consecuencia de convertir cualquier guerra no defensiva en un ilícito de derecho positivo.

Ahora bien, esta calificación de la guerra como ilícito —-según aclara el autor-es posible porque el concepto de «ilícito», que constituye un término primitivo y, por ello, fruto de una opción, ha sido definitido como «acto (informal) probibido», prefiriendo tal definición estipulativa a la de KELSEN, que define el ilícito como «cualquier acto al que el ordenamiento asocia una sanción». Las implicaciones teóricas y las consecuencias prácticas de esta opciones son relevantes. En efecto, pues para KELSEN, en ausencia de sanciones previstas por el orden jurídico, la guerra no es un ilícito e incluso en algunos casos se la concibe como sanción, con paradójica recuperación para el ordenamiento jurídico de un fenómeno que es su negación. En cambio, para FERRAJOLI la guerra sigue siendo un ilícito aun en ausencia de sanciones (en seguida veremos que quizá esa ausencia no es tan absoluta); mientras una tal ausencia sirve solamente para señalar la existencia de una laguna en el ordenamiento, que deberá colmarse.

No es frecuente que se llame a un jurista empírico a confrontarse con la guerra y con pretensiones fundadas en el comportamiento bélico. Lo que hace que, si llamado a una tarea semejante, sea todavía más imperiosa la exigencia de extremar la consciencia al decantarse por alguna de las opciones hermenéuticas implícitas en tales operaciones; precisando y delimitando el espacio abierto a las mismas, explicitándolas como tales y extrayendo con rigor sus consecuencias. Tanto para el jurista empírico como para el teórico, tal espacio está representado por los presupuestos de la calificación jurídica de la guerra, y debe colmarse de forma que las opciones realizadas y las consecuencias que se deriven sean congruentes con los datos normativos relativos al fenómeno, que son, sobre todo, los que ofrecen el Derecho internacional y la Constitución. 
Es por lo que suscita preplejidad una sentencia, relativamente reciente, de las Secciones Unidas de la Corte de Casación civil italiana, la n. ${ }^{\circ} 8157 / 2002$, de 5 de junio, que parece haber discurrido completamente al margen de ese modo de operar.

El caso judicial en el que intervino la Corte tenía que ver con una demanda de resarcimiento por daños promovida contra el Estado italiano por los parientes de dos ciudadanos serbios, fallecidos como consecuencia del bombardeo aéreo del edificio de la radiotelevisión de Belgrado, realizado el día 23 de abril de 1999 por las fuerzas de la OTAN durante la guerra de Kosovo.

Llamada a pronunciarse acerca de la procedencia de la demanda, la Corte la declaró totalmente improcedente por defecto absoluto de jurisdicción (construcción procesal civil, por lo demás, abandonada desde hace más de un decenio, pero éste es un aspecto secundario de la cuestión).

Vale la pena detenerse un instante en las razones de la Corte para estimar del todo improcedente la demanda de resarcimiento, centradas en que los actos del Estado en la conducción de hostilidades bélicas son jurisdiccionalmente infiscalizables en tanto que manifestación de una función política atribuida por la Constitución al Gobierno, en relación con la cual no puede concebirse un interés jurídicamente protegido a que tales actos asuman o no un determinado contenido. En otras palabras, frente a la dirección de la guerra, los derechos fundamentales vitales, aun cuando calificados de inviolables por la Constitución y el Derecho internacional, se degradan a interés de puro hecho, sin que sea preciso indagar siquiera si la guerra, de cuya gestión se discute, fue o no una guerra de defensa. Derechos fundamentales y prohibición de la guerra no defensiva, igualmente sancionados por la Constitución, se degradan en esta perspectiva a meros flatus vocis.

El primer aspecto problemático de tal decisión radica en que extrapola del comportamiento global, la guerra, el fragmento de comportamiento representado por la conducción de las actividades bélicas, que constituye sólo una parte de aquél. En efecto, si es cierto que, según el ordenamiento constitucional, la conducción de las operaciones bélicas está atribuida al Gobierno, no lo es menos que el mismo ordenamiento prescribe que la decisión relativa a ese comportamiento general, cuya concreta modalidad operativa se discute, corresponde al Parlamento, que debe asimismo deliberar sobre los poderes del Gobierno para el caso (art. 78 de la Constitución italiana); y, sobre todo, que, al decidir sobre este punto, las Cámaras están vinculadas por el principio fundamental que estigmatiza como totalmente ilícita (repudia) la guerra no defensiva. La afirmación de que las acciones realizadas en la conducción de las hostilidades bélicas constituyen el ejercicio de una función política, frente a la que no existen intereses dignos de protección, no aclara en modo alguno los nexos de la regla enunciada con las otras dos reglas antes recordadas, y en particular si la misma vale también en el caso de una guerra sobre la que no deliberaron las Cámaras o de una guerra (que hubiera sido o no objeto de deliberación) contraria al art. 11 de la Constitución.

El segundo punto problemático tiene que ver con el carácter absoluto de la afirmación según la cual no existirían intereses protegidos frente a la opción entre modalidades de conducción de las operaciones bélicas, ni siquiera en el caso de que convenciones internacionales ratificadas por el Estado italiano establezcan límites e interdicciones en relación con las mismas. 
En lugar de la transparencia en orden a la definición de la guerra sub specie iuris, se hace hincapié en una pretensión de infiscabilidad de la «función política» ínsita en la elección del modo de conducir cualquier operación bélica, acogiendo implícitamente una noción de la soberanía, propia de siglos pasados, insensible a los cambios producidos en el paradigma del Estado constitucional y democrático de Derecho, en el que la soberanía pertenece al pueblo, es decir, a cada uno de los ciudadanos de carne y hueso, disolviéndose, de este modo, para funcionar como límite a los poderes constituidos.

Es cierto que el pronunciamiento toma en cuenta los posibles límites de tal soberanía derivados de las convenciones internacionales ratificadas por el Estado italiano. En particular, del Procolo de Ginebra de 1977 y de la Convención Europea de Derechos Humanos, que disciplinan explícitamente la conducción de las hostilidades asegurando la protección de los civiles en caso de ataques. Pero el propio pronunciamiento considera que ni siquiera tales disposiciones (cuyo nexo con el art. 2 de la Constitución italiana, que reconoce y garantiza los derechos inviolables del hombre, no se indaga) sirven para fundar un interés jurídicamente protegido de las personas que, por la violación de aquéllas, resulten lesionadas en sus derechos fundamentales. Porque tales disposiciones, aun introducidas en el ordenamiento interno por las respectivas leyes de ratificación, regularían únicamente las relaciones entre Estados, y también porque —se añade- «los propios tratados [...] preven saciones para los casos de responsabilidad [...] y señalan los Tribunales internacionales competentes para afirmarla». Prescindiendo de cualquier otra consideración, la presencia de tales disposiciones debe relacionarse con el nuevo texto del art. 117.1 de la Constitución italiana (en vigor en la época del pronunciamiento), según el cual las leyes del Estado deber respetar, so pena de invalidez, los vínculos derivados de las obligaciones internacionales; que, así, son también performativos del ordenamiento interno y de las calificaciones que del mismo se sigan (como el carácter de infiscalizable que se predica de la conducción de las hostilidades bélicas). Y lo cierto es que habría sido necesaria una exploración de este género para salir de dudas acerca de la contradicción con la Constitución de la supuesta normativa interna o, mejor, de la reconstrucción de la misma en sentido obstativo a la configuración de un interés protegido de titularidad de las personas perjudicadas por la conducción de las operaciones bélicas en contradicción con aquel vínculo.

De este modo se elude una temática cargada de implicaciones teórico-prácticas, que hoy preocupa a los juristas no menos que a los tribunales, y sobre la que la obra de FERRAJOLI ofrece una atenta mirada histórica y una perspectiva teórica de notable relieve, a través del paradigma de los «grados de federalismo» como brújula para orientarse en el universo de los ordenamientos. Aunque quizá sería mejor decir que, más que eludirla, se la despacha con una opción inconsciente a favor de la tesis dualista de la impermeabilidad de los ordenamientos estatal e internacional, que data de comienzos del siglo pasado y ha sido prácticamente desmentida por la propia Constitución.

Por lo demás, el señalado es un horizonte temático que, apenas dos años más tarde, llevaba a las mismas Secciones Unidas civiles de la Corte a afirmar que «el respeto de los derechos inviolables de la persona humana ha asumido el valor de principio fundamental del ordenamiento internacional», hasta el punto de prevalecer sobre la norma que impone a los Estados la obligación de abstenerse de ejercer la jurisdicción en relación con los Estados extranjeros y de legitimar el ejercicio de la jurisdicción italia- 
na en respuesta a la demanda de resarcimiento promovida por un ciudadano italiano contra la República Federal Alemana por los daños sufridos como consecuencia de un mandato de captura, deportación y sumisión a trabajo forzado, por efecto de la conducción de las actividades bélicas por parte del Estado alemán durante el segundo conflicto mundial (sentencia n. ${ }^{\circ}$ 5044/2004, de 11 de marzo).

La obligada distinción de este último supuesto del que fue objeto del pronunciamiento de 2002 no excluye en modo alguno que la trama justificativa de la decisión, tanto en uno como en otro caso, debiera confrontarse con el principio fundamental de respeto de los derechos inviolables de la persona humana, so pena de falta de transparencia de la decisión que hubiese omitido ese examen. No es casual que el pronunciamiento de 2004 — que llevó a cabo esa verificación- llegara a resultados opuestos a los del de 2002, en la cuestión relativa a la justiciabilidad de la conducción de operaciones bélicas (de forma coherente con el derecho internacional general, cuyos preceptos ha incorporado nuestra Constitución, en el art. 10).

\section{MÉTODO. INFLACIÓN, DESORDEN LEGISLATIVO, PLURALISMO DE LOS ORDENAMIENTOS}

Las consideraciones que acabo de hacer permiten señalar otro específico motivo de interés de la obra de FERRAJOLI para el jurista empírico.

Acaba de verse cómo la exigencia de transparencia de las opciones que implican las interpretaciones de los jueces reclama la coherencia de aquéllas y de las consecuencias que conllevan con los datos normativos relativos a la materia propia del supuesto considerado; en particular con los datos recabables de las fuentes de superior rango, como la Constitución, las convenciones y los tratados internacionales. Ahora bien, tales datos contienen a menudo enunciados normativos cuyo lenguaje evoca más bien las declaraciones de principios que la fría consecuencialidad del Côde Civil. De aquí la tendencia - ¿tentación? - del jurista positivo y del juez a atribuir a tales enunciados un valor político-programático más que jurídico, cuando no a ignorarlos del todo. Es el fenómeno bien conocido de la experiencia jurídica italiana de los primeros decenios de la vida de la República, de la calificación de muchas normas de la Constitución como «programáticas» y la consiguiente esterilización de las mismas. Fenómeno, por cierto, debido en parte no desdeñable a una suerte de resistencia político-cultural al nuevo orden, pero también a la particular formación del jurista positivo, al eco de argumentos teóricos kelsenianos, a la falta de aparatos conceptuales adecuados para captar en plenitud el nuevo paradigma del Derecho. La consecuencia, para el juez, era —y lo es aúnuna ruptura del vínculo de sujeción a la «ley», del todo inconsciente e incluso subjetivamente vivida, y en ocasiones sufrida, como una obstinada reafirmación de ese vínculo.

Esta paradoja se produce en el terreno de un equívoco semántico en torno al término «ley», de cuyo ámbito resulta excluido todo lo que parece reconducible al concepto de ley tradicionalmente entendido.

FERRAJOLI ofrece un poderoso auxilio para la superación de este equívoco.

Ante todo, llamando con insistencia al intérprete al cumplimiento del deber de no asignar a los enunciados de las fuentes de superior rango el valor de un mero «flatus vo- 
cis» y subrayando el deber metodológico de asignar un significado a todos los enunciados normativos.

Después, construyendo un aparato conceptual centrado en las categorías axiológicas de antinomias y lagunas, reinterpretadas con referencia a una estructura del ordenamiento articulada en grados, de modo que aquellos términos asumen un valor diverso y producen consecuencias diversas según que las antinomias y lagunas se constaten entre productos de fuentes del mismo grado o de grado diverso; y acuñando, para esta última hipótesis, la categoría del derecho ilegítimo, desvelando así la falacia KELSENiana de la identificación (o confusión) del Derecho con la garantía, tributaria de una larga tradición.

En fin, proporcionando — como ya he apuntado — con las definiciones de federación y confederación y con la introducción del concepto de «grado de federalismo», los instrumentos para navegar en las aguas no límpidas de los ordenamientos multinivel.

En efecto, hace ya tiempo que los juristas más avisados denuncian la dificultad de hallar una ruta medianamente segura en el paisaje jurídico de este inicio de milenio dominado por lo impreciso, lo incierto, lo inestable, por el superponerse de las fuentes nacionales, supranacionales, internacionales, incluso consuetudinarias (piénsese en la lex mercatoria, analizada por el mismo FERRAJOLI). Un desorden que es el resultado de las grandes transformaciones que se producen a un ritmo acelerado a escala planetaria, a través de la creciente crisis del Estado-nación, la progresiva superación de monopolio estatal del Derecho, la globalización económica y la inversión de la relación entre soberanía y economía.

Al mismo tiempo, es cada vez más fuerte la necesidad de reglas, de Derecho, en suma, de «pluralismo ordenado», según una fórmula feliz.

Principia iuris sale al paso de esta necesidad con la respuesta de una teoría a la altura de las inéditas novedades que la producen.

\section{UNA OBSERVACIÓN Y TRES PREGUNTAS}

Antes de concluir, una consideración y tres preguntas al autor.

La primera es una reflexión con la que entro en un territorio que no es el mío, confiando en la indulgencia del lector.

Toda la obra está concebida bajo la enseña de una neta separación entre ética y Derecho. No es que se prive de relevancia a la primera, que, por el contrario, resulta asumida como fundamento de una de las tres divergencias deónticas conceptualizadas: la que se da entre el «deber ser» del derecho positivo, incluido su nivel constitucional o superior, y el derecho positivo tal como es, incluido su nivel constitucional o superior. Pero — cualesquiera que sean los contenidos éticos incorporados al derecho positivo-, FERRAJOLI, justamente, a mi juicio, rechaza la fórmula de AlEXY según la cual una norma pierde validez jurídica si es sumamente injusta. Entiendo que la categoría de la «suma injusticia» está en la base de la revolución copernicana realizada en el paradigma del Derecho a raíz de la segunda guerra mundial y en la fundación de la tabla de valores jurídicos puestos como nivel supraordenado al ordenamiento jurídi- 
co internacional y a los ordenamietnos jurídicos internos dotados de una constitución coherente con aquellos valores. Pero, precisamente, ese paradigma ha constituido la «justificación» de aquella revolución, y no una consecuencia de la misma incorporada a la noción actual de Derecho. Que luego el Derecho actualmente vigente prevea, por ejemplo, la obligación de desobedecer un acto de autoridad, incluso una ley, atentatorios contra derechos fundamentales positivamente establecidos y cuya violación sea configurada como un crimen, sólo significa que la instancia moral, que estaba en la base de la revolución de la que ha nacido el nuevo orden, ha producido esta nueva regla jurídica cuyos contenidos están exactamente delimitados por aquellos bienes que el nuevo orden ha definido como inviolables; y no que una ley que mañana fuese sentida como «sumamente injusta» pueda, sólo por esto, perder su validez, aun cuando no viole alguno de aquellos bienes.

Puede ser que mañana la ciencia nos diga que los animales son seres dotados de conciencia, capacidad de imaginar el mal y de sufrir como seres humanos, etc., y que por tanto resulte insoportable el hecho de que existan los mataderos. Sólo por esto el derecho a gestionar un matadero no perdería automáticamente su validez. Tal «suma injusticia» podría, al máximo, motivar una nueva revolución que se llevaría por delante la ley que autoriza los mataderos (y el orden de que la misma es expresión), o, de forma menos dramática y más plausible, podrá inducir nuevas leyes o incluso nuevas normas constitucionales; pero, ciertamente, no podrá invalidar, desde dentro del ordenamiento considerado y sin ninguna intervención nomodinámica, la ley en cuestión.

Opinando de otro modo, se corre el riesgo de expulsar fuera del ámbito del derecho la protección de aquellos bienes cuya violación, bic et nunc, hace inválido el acto que atente contra ellos; o de bloquear la misma evolución del sentimiento moral hacia la protección de sólo aquellos bienes cuya violación se valore en un cierto momento como intolerable, precluyendo absurdamente que en algún mañana pueda llegar a ser sumamente injusta también la violación de otros bienes y que esta clase de sentimiento pueda motivar una crítica externa del Derecho existente.

$\mathrm{Y}$ voy a las cuestiones.

\section{Separación de poderes y leyes de interpretación auténtica}

La primera se refiere a la relación entre separación de poderes (con particular referencia a la frontera que separa el poder legislativo del poder judicial) y leyes de interpretación auténtica, que necesariamente inciden en los juicios en curso que tengan por objeto la aplicación de la ley auténticamente interpretada.

Uno de los aspectos del desorden ya aludido está representado —especialmente en Italia- por la inflación legislativa, por la proliferación de las leyes y sobre todo de las leyes-acto (leggine) que se superponen, se derogan, se persiguen, y que a menudo duran una mañana. Con frecuencia, estas últimas consisten en una sola disposición, insertada en un texto que trata de los asuntos más dispares, dirigida a regular algún aspecto particular de una materia más amplia relativa a clases de sujetos (trabajadores, pensionistas, usuarios de servicios públicos, etc.); aspecto sobre el que existe un contencioso al que los órganos jurisdiccionales dan respuestas, que, no es extraño, pueden 
resultar divergentes. Así, la disposición de interpretación auténtica interviene sobre la norma que regula la cuestión sub iudice, determinando el resultado de la litis, o mejor, de las litis en curso. En Italia, las llamadas leyes financieras (presupuestarias) de los últimos años, ofrecen un rico muestrario de disposiciones de esta clase. A veces la intervención legislativa explicita la propia finalidad invasiva con fórmulas del tipo «para poner fin al ingente contencioso...»; más a menudo se limita a enunciar el significado que debe atribuirse al enunciado sobre cuya interpretación existe controversia.

La Corte Constitucional italiana, llamada a decidir en numerosas ocasiones sobre la legitimidad de tales intervenciones desde distintos puntos de vista, no ha afirmado que sean ilegítimas por principio, pero ha declarado más de una vez su contrariedad con la Constitución desde el punto de vista de la violación del canon de la razonabilidad, con referencia a perfiles peculiares de la vicisitud objeto de consideración y sin que pueda extraerse de tales pronunciamientos una línea de separación suficientemente clara.

Recientemente, el Tribunal Europeo de Derechos Humanos (sentencia Scordino, de 29 de julio de 2004, y, antes, sentencia Anagnostoupolos c. Gobierno griego, de 7 de noviembre de 2000) ha entendido que la injerencia del legislador en los procesos en curso viola el art. 6 de la Convención Europea de Derechos Humanos en la parte en que tal norma asegura el derecho a un justo proceso ante un juez tercero, independiente e imparcial.

Preguntas: a) ¿Es compatible con la separación de poderes la interpretación auténtica, o mejor, la retroactiva que es inherente a la misma (que el legislador-intérprete podría ciertamente excluir estableciendo que la interpretación dictada no se aplique a los juicios pendientes)?

b) En caso de respuesta positiva, ¿la afirmada compatibilidad se extiende también a la hipótesis de que la disposición retroactiva incida en controversias pendientes ya en sede de legitimidad o, incluso, después de que la Corte de Casación en el ejercicio de su propia competencia (asegurar la uniforme interpretación del derecho) se hubiera pronunciado?

\section{Contrato de trabajo subordinado: ¿«decisión» o «acto constitutivo»?}

Segunda pregunta, que formularé brevemente, aunque toca cuestiones centrales de la teoría.

Parto de la distinción de los actos preceptivos en decisiones y actos constitutivos, estando caracterizados los primeros por la capacidad de producir como efectos las situaciones y normas que ellos mismos prescriben, en el respeto de la normativa de superior rango; y los segundos por la circunstancia de que su significado prescriptivo sea un estatus jurídico. Pues bien, siendo así, ¿el contrato de trabajo subordinado está integrado en la primera categoría (que comprende, ciertamente, los contratos de cambio) o más bien, y sólo tendencialmente, en la segunda, a la que, por ejemplo, ciertamente, pertenece el matrimonio? La pregunta está justificada por la observación de que, al menos tendencialmente, FERRAJOLI adscribe las normas sobre el trabajo subordinado al Derecho público, de manera que la autonomía de las partes que estipulan el contrato 
de trabajo subordinado quedaría limitada a la sola formalización del contrato, cuyos efectos brotarían luego de la ley o de las fuentes colectivas.

\section{Las lagunas y sus remedios. Derechos fundamentales y ponderación}

En fin, la tercera y última pregunta, que se articula en dos cuestiones.

a) En el proyecto de democracia constitucional expuesto en el segundo volumen de Principia iuris, FERRAJOLI indica, como posibles remedios a las lagunas relativas a los derechos fundamentales, un perfeccionamiento de la respuesta, no decisiva, ofrecida por las constituciones portuguesa y brasileña (señalamiento de la laguna al Parlamento por parte del Tribunal Constitucional), a través de la introducción - junto a este mecanismo- de la obligación a cargo del propio Parlamento de decidir en un breve plazo.

En esta perspectiva, ¿qué indicaciones y proyectos de desarrollo cabría extraer del mecanismo introducido por el Protocolo undécimo de la Convención Europea de Derechos Humanos, que habilita al Tribunal de Estrasgurgo para condenar al Estado que incumpla?

Más en general, el mecanismo de la condena del Estado que incumpla - asimismo previsto en el Tratado CEE (art. 228.3, ex art. 171), cuando el Estado miembro no haya adoptado, dentro del término fijado por la Comisión las medidas a que obliga la ejecución de una sentencia del Tribunal de Justicia - podría, tal vez, completar la previsión de la obligación a cargo del Parlamento de decidir sobre el señalamiento de la laguna, evitando que tal obligación quede desprovista de una sanción que no sea, una vez más, la meramente política.

En la misma línea, quedaría todavía por decidir si la condena debe modelarse sobre la prevista en el Protocolo de la Convención Europea de Derechos Humanos (condena a favor del sujeto que lamenta las consecuencias prejudiciales de la laguna, con una suerte de valorización del ius litigatoris) o bien sobre la prevista por el Tratado CEE (condena a favor de un fondo sustraido a las determinaciones del Parlamento y del Gobierno, con una suerte de valorización del ius constitutionis).

b) La segunda cuestión, sólo en parte relacionada con la que acaba de apuntarse, hace referencia a otro orden de problemas.

Entre las lagunas que puede presentar el ordenamiento en relación con las normas constitucionales (o más en general, superiores), destinadas a la tutela de los derechos fundamentales, está comprendida también la ausencia de preceptos penales, indispensables en algunos casos para la garantía de aquellos derechos.

Ahora bien, una situación del género es la que, a juicio de autorizados juristas, se produce en el ordenamiento italiano en relación con la disposición constitucional del art. 13.4 de la Constitución. Éste -único caso en la misma de norma que, explícitamente, imponen una obligación de sanción-, prescribe castigar «todo acto de violencia física o moral sobre personas sometidas a restricciones de libertad». Se trata de una obligación confirmada, y tratada de forma aún más precisa, por la Convención Internacional contra la tortura, ratificada por el Estado italiano por Ley 648/1984, en su art. 4. 
Aunque son muchos los que opinan que esta Convención obliga a Italia a introducir en su legislación penal un específico delito de tortura y a pesar de que se han presentado muchos proyectos de ley en los últimos doce años, algunos de los cuales estuvieron cerca de la aprobación definitiva, sin embargo, hasta la fecha, la legialación penal italiana no conoce el delito de tortura, a pesar de la disposición constitucional que impone a la potestad legislativa del Estado y las Regiones respetar las obligaciones internacionales (art. 117.1 de la Constitución italiana, según resulta de la Ley constitucional 3/2001).

Y tal laguna se manifiesta no sólo como violación de la obligación internacional derivada de la Convención, sino también, en algunos aspectos, enseguida se verá, como violación de la obligación impuesta al legislador por el recordado art. 13.4 de la Constitución italiana.

En efecto, es muy cierto que nuestro Código Penal castiga con la reclusión de hasta treinta meses al funcionario que someta a «medidas de rigor no permitidas por la ley» a una persona detenida o presa (art. 608), pero es lícito dudar de que esta disposición baste para hacer realidad la garantía del derecho fundamental a la integridad y la dignidad de la persona, enérgicamente proclamado por la Constitución y el ordenamiento internacional, en particular si la norma aludida se pone en relación con las otras del Código relativas a la prescripción del delito (arts. 157-161 del CP) que establecen términos de prescripción calibrados en función de la entidad de la pena del tipo (en el caso, cinco años a partir de la fecha de ejecución del hecho y, de concurrir actos de interrupción, nunca más de siete años y medio). De manera que, en la mayor parte de los casos, la disposición del art. 608 del Código Penal corre el riesgo de quedar en un mero flatus vocis.

No parece que la laguna pueda colmarse a través de la interpretación del juez ordinario, como, en otro contexto, sucedió en Francia a mediados de los años ochenta con la sentencia del Tribunal de Casación en el caso Barbie, que reconoció la imprescriptibilidad de los crímenes contra la humanidad atribuidos al imputado, por considerar que tal regla, aun no escrita en la ley, formaba parte del Derecho francés, como parte que era del Derecho internacional general, al que el Derecho de la República debía acomodarse. En efecto, aparte de cualquier otra consideración, la noción de crimen contra la humanidad está hoy positivizada por el Estatuto del Tribunal Penal Internacional, ratificado por Italia mediante la Ley 232/1999, y en su definición no entran los hechos de tortura cometidos por un agente estatal fuera de los casos de «generalizado y sistemático ataque a las poblaciones civiles» (art. 7.1).

Esta es la cuestión: excluida, obviamente, la posibilidad de colmar la laguna a través de la intervención directa de la Corte Constitucional en sustitución del legislador, podría afirmarse que la crisis de legalidad constitucional, puesta de relieve en el cuadro normativo que se ha descrito, configura, además de una laguna, una antinomia (si se quiere, ésta como consecuencia de aquélla) en tanto que el régimen de prescripción, leído en conexión con la única norma incriminadora aplicable y valorado a la luz de los tiempos medios del proceso penal, tal como los aprecia también la jurisprudencia del Tribunal Europeo de Derechos Humanos, banaliza de hecho la punibilidad de la tortura, aun prevista en abstracto, haciéndola inefectiva.

Así las cosas, la antinomia se produciría entre los arts. 157 y siguientes leídos en conexión con el art. 608 del Código Penal, de una parte, y, de otra, los arts. 13.4 y 117.1 
de la Constitución (integrado el segundo con la obligación internacional de castigar). Y la intervención solicitada a la Corte sería «declarar la inconstitucionalidad del conjunto normativo denunciado en la parte en que no exceptúa de la prescripción los hechos castigados por el art. 608 del Código Penal constitutivos de tortura en el sentido del art. 1 de la Convención de 1984».

Sin embargo, este planteamiento encuentra el límite que el control de legitimidad de las leyes sufre por efecto de los principios constitucionales de legalidad e irretroactividad de las normas penales.

En efecto, la disciplina de la prescripción es inherente a la punibilidad y, por esta vía, debería recaer en el ámbito de la garantía del art. 25.2 de la Constitución (según ha afirmado en numerosas ocasiones la Corte Constitucional, por ejemplo, ordenanzas n. ${ }^{\text {os } 337 / 1999}$ y 317/2000). Garantía a propósito de la cual la propia Corte ha afirmado recientemente que es «condición necesaria para la libre autodeterminación individual», añadiendo que la misma «representa [...] un valor absoluto, no susceptible de ponderación con otros valores constitucionales, no sólo en relación con la hipótesis de la nueva incriminación, sino también con referencia a la de la reforma peyorativa del tratamiento sancionatorio de un hecho ya castigado» (sentencia n. ${ }^{\circ} 394 / 2006$ ).

Sin embargo, la misma Corte - que desde hace decenios se afana en torno a este nudo problemático - ha tenido ocasión de afirmar, precisamente a propósito del régimen de la prescripción, que una intervención en la materia que se traduzca en un tratamiento perjudicial para el imputado, con violación del principio de legalidad sancionado en el art. 25.2 de la Constitución, le está precluida «siempre que la disciplina (denunciada) no sea fruto de una opción abiertamente arbitraria o injustificada» (ordenanzas n. ${ }^{\circ} 337 / 1999$ y $317 / 2000$, ya citadas).

Así pues, parecería que la patente arbitrariedad o falta de justificación de la disciplina dictada por el legislador ordinario para la prescripción, sería un contralímite al principio de legalidad. En tales hipótesis (prescripción regulada de forma claramente arbitraria o injustificada), no sería aquel «valor absoluto, no susceptible de ponderación» a que se refiere la sentencia n. ${ }^{\circ} 394 / 2006$, sino que tendría que ser ponderado con el principio que niega validez a los productos del legislador teñidos de patente arbitrariedad o irrazonabilidad y/o — cabría añadir, llegados a este punto- que contradigan las obligaciones indeclinables que el propio legislador encuentra en la Constitución (art. 13.4) o en el Derecho internacional.

La aparente contradicción - testimono de una trabajosa búsqueda/construcción de coherencia del ordenamiento- puede quizá superarse observando que el carácter absoluto del principio de irretroactividad de la ley penal se mantiene como tal en lo relativo a su «núcleo duro», que se cifra en la protección de la «libre autodeterminación individual» que permite al ciudadano (y más en general al sujeto) hacer todo lo que no está prohibido; pero ese rasgo de rigor se atenúa en lo relativo a la disciplina extrínseca a la prohibición, en sí misma considerada, como sin duda es la disciplina de la prescripción, que mira a la valoración del «interés general de no perseguir los delitos respecto de los que el largo tiempo transcurrido desde que fueron cometidos hubiera hecho desaparecer o atenuarse notablemente la alarma en la conciencia común» (Corte Constitucional n. ${ }^{\text {s }}$ 207/1971 y 254/1985). La libertad del individuo frenta a tal disciplina no 
es en modo alguno comparable con la libertad del que actúa con la conciencia de no violar la ley. Aquí el sujeto actúa más bien sabiendo que viola la ley y acaso contando con el breve plazo de prescripción para escapar a las consecuencias del delito. Un cálculo — que apuesta por la impunidad (que no parece ser un valor) — inherente a la opción de infringir la ley penal, que no resulta merecedor de protección en perjuicio de fundamentales reglas de convivencia, como las que imponen al Estado, dentro de ciertos límites, el deber de castigar.

Pues bien, frente a este aspecto de la crisis de la democracia constitucional, ¿es impertinente invitar al autor de Principia iuris, que es también el autor de Diritto e ragione, a la interlocución?

(Traducción de Perfecto Andrés Ibáñez) 
